\title{
Torakolomber kırıklarda minimal invaziv yaklaşımlar
}

\author{
Minimally invasive approaches to thoracolumbar fractures
}

\author{
İsmail Daldal ${ }^{1}$, Alpaslan Şenköylü ${ }^{2}$
}

\begin{abstract}
'S.B. Sakarya Üniversitesi Eğitim ve Araştırma Hastanesi, Ortopedi ve Travmatoloji Anabilim Dalı, Adapazarı, Sakarya ${ }^{2}$ Gazi Üniversitesi Tıp Fakültesi, Ortopedi ve Travmatoloji Anabilim Dalı, Ankara
\end{abstract}

\begin{abstract}
Minimal invaziv omurga cerrahisi, omurganın görüntüleme yöntemleri eşliğinde perkütan, minimal açık veya endoskopik girişimlerini kapsar. Perkütan pedikül vida tespiti ve mini-açık anterolateral retraktör yardımlı yaklaşımlar dahil minimal invaziv tekniklerdeki ilerlemeler, kan kaybını, operasyon süresini ve ameliyat sonrası ağrıyı azaltarak uygun şekilde uygulandığında cerrahi sonuçları iyileştirmektedir. Bu yaklaşımlar temel olarak konvansiyonel açık yaklaşımların kas disseksiyonu aşamasında kaybedilen kas ve iskelet kan akımının ve innervasyonun korunmasıyla teorik avantaj sağlar. Minimal invaziv yöntemlerin bu avantajları dolayısıyla torakolomber kırıklı hastalarda da kullanımı artmaktadır.
\end{abstract}

Anahtar sözcülkler: torakolomber kırıklar; minimal invaziv; perkütan pedikül vidalama; vertebroplasti; kifoplasti
Minimally invasive spinal surgery involves percutaneous, mini-open or endoscopic approaches of the spine by using perioperative imaging methods. Advances in minimally invasive techniques, including percutaneous pedicle screw fixation and mini-open anterolateral retractor assisted approaches, improve surgical outcomes when applied properly, reducing blood loss, operative time, and postoperative pain. These approaches provide a theoretical advantage mainly by preserving the muscular and skeletal blood flow and innervation that have been lost in the muscle dissection phase of conventional open approaches. Therefore, these minimally invasive methods are increasingly used in patients with thoracolumbar fractures.

Key words: thoracolumbar fractures; minimally invasive; percutaneous pedicle screw fixation; vertebroplasty; kyphoplasty

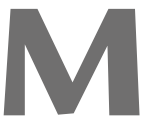

inimal invaziv omurga cerrahisi, omurganın görüntüleme yöntemleri eşliğinde perkütan, minimal açık veya endoskopik girişimlerini kapsar. Perkütan pedikül vida tespiti ve mini-açık anterolateral retraktör yardımlı yaklaşımlar dahil minimal invaziv tekniklerdeki ilerlemeler, kan kaybını, operasyon süresini ve ameliyat sonrası ağrıyı azaltarak uygun şekilde uygulandığında cerrahi sonuçları iyileştirmektedir. ${ }^{[1,2]}$ Bu yaklaşımlar temel olarak konvansiyonel açık yaklaşımların kas disseksiyonu aşamasında kaybedilen kas ve iskelet kan akımının ve innervasyonun korunmasıyla teorik avantaj sağlar. ${ }^{[3]}$

Torakolomber kırıkların tedavisinde halen fikir birliği olmamakla birlikte, cerrahi kararın verilmesi ve uygulanacak cerrahi yaklaşımların çeşitliliği nedeniyle cerrahların odak noktası olmuştur. Çeşitli omurga yaralanması tipleri için biyomekanik, patofizyolojik ve doğal sürecin daha iyi anlaşılması, tedavi seçeneklerinin daha iyi belirlenmesine olanak sağlamıştır ve cerrahi müdahale endikasyonlarını belirlemeye yardımcı olmuştur.

Torakolomber vertebra kırıkları cerrahisinde her biri kendine özgü avantajları olan posterior, anterior veya kombine anterior-posterior yaklaşımlar düşünülebilir. Tarihsel olarak, posterior spinal yaklaşımlar, geniş segment dorsal dekompresyonlu açık tespit teknikleri ve gerekirse sagittal dengenin oluşturulması için anterior kolonun desteklenmesini içermiştir. Benzer şekilde, torakotomi kullanan anterior yaklaşımlar, nöral elemanları doğrudan açmak ve vertebra korpusuna uygun implantların uygulanması yoluyla biyomekanik desteği sağlamak için gerçekleştirilebilir.

Son zamanlarda, minimal invaziv teknikler, yaklaşım sırasında paraspinal doku hasarını en aza indirgeme avantajları nedeniyle önem kazanmıştır. Minimal invaziv yaklaşımların spinal travmada kullanılması, hasta morbiditesini azaltması, hızlı iyileşme ve erken işe

- İletişim adresi: Dr. Alpaslan Şenköylü, Gazi Üniversitesi Tıp Fakültesi, Ortopedi ve Travmatoloji Anabilim Dalı, Beşevler, Ankara Tel: 0312 - 2025526 e-posta: drsenkoylu@gmail.com

- Geliș tarihi: 1 Kasım $2018 \quad$ Kabul tarihi: 1 Kasım 2018 
dönüş süreci gibi potansiyel avantajları sağlayabilir. $\mathrm{Bu}$ yazıda, torakolomber yaralanmalarda kullanılan minimal invaziv tekniklerin olumlu ve olumsuz yönleri derlenmiştir.

\section{PERKÜTAN POSTERIOR SPINAL TESPIT}

Torakolomber omurga kırıklarında uygulanan perkütan pedikül vidası ile tespit, stabil olmayan kırıkların internal tespitine izin verirken ameliyat sonrası düzeltilen sagittal dengenin korunmasına yardımcı olur. Instabil torakolomber kırıklarda ve eksternal breys tedavisini tolere edemeyecek hastalarda kırık bölgesindeki segmental hareketi sınırlamak için pedikül vidaları yardımıyla posterior internal tespit gerekmektedir. Perkütan pedikül vidası yerleştirmenin, geleneksel açık posterior yaklaşımlara göre, paraspinal kas sisteminin geniş çaplı retraksiyonunu, devaskülarizasyonu ve denervasyonunu gerektirmemesi nedenli önemli avantajlara sahip olabileceği ileri sürülmüştür. Ayrıca, perkütan minimal invaziv pedikül vidası ile posterior tespitin daha kısa operasyon süresi, daha az kan kaybı ve daha az ağrıya neden olduğu ve sonuçta daha hızı ıyileşme ve daha kısa hastanede kalış süresi gibi avantajları çeşitli çalışmalarda bildirilmiştir. ${ }^{[3,4]}$

Posterior enstrümantasyon sonrası ilgili segmentte spinal artrodez gerektiği görüşü genel kabul görmesine rağmen, artrodez oluşacağı öngörülen geleneksel posterior tespit tekniklerine göre füzyon olmaksızın tespiti karşılaştıran birçok çalışma, uzun dönem izlemde benzer sonuçlar göstermiştir. ${ }^{\left[{ }^{[-7]}\right.}$

Torakolomber vertebra kırıklarında travmanın oluş mekanizması çok iyi bilinmelidir. Burst kırıkları ve fleksiyon-distraksiyon tipi kırıkların birbirinden farklı aşırı yüklenme mekanizmalarıyla olduğu unutulmamalı ve tedavi planlanması yapılırken bu farklılıklar dikkate alınmalıdır.

\section{Torakolomber Burst Kırıkları}

Posterior artrodezin, posttravmatik kifozun ilerlemesinin önlenmesi için gerekli olduğu düşünülmesine rağmen füzyon olmaksızın perkütan minimal invaziv posterior tespit sonrası da iyi sonuçlar bildirilmektedir. Perkütan pedikül vida tespiti yöntemiyle füzyon olmaksızın tespiti inceleyen bir çalışmada, enstrümantasyonun ameliyattan sonraki 9-12 ay sonra çıkarılması, klinik sonuçların kötüleşmesine neden olmamasına rağmen, orijinal kifoz düzeltmesinin miktarında küçük ancak istatistiksel olarak anlamlı bir düşüşe neden olmuştur. ${ }^{[8]}$ Perkütan pedikül vida tespitinin posterior açık füzyon ile doğrudan karşılaştırıldığı diğer çalışmalarda, uzun dönem takipte iki yöntem arasındaki sonuçlarda bir fark görülmemiştir. ${ }^{[9-10]}$ Perkütan posterior spinal enstrümantasyonun uzun dönem başarılı sonuçları görülmeye devam ederken, bu bilgiler ışığında bu yöntemin uygun hastalara uygulandığında spinal sagittal dengeyi sürdürmek için yeterli biyomekanik destek sağladığını düşündürmesi olasıdır. Cerrahın, minimal invaziv yöntemlerle tedavi etmeyi düşündüğü hastalara, ameliyat sonrası kifoz riskinin yüksek olmamakla birlikte bulunduğunu ve bunun gelişmesi durumunda daha büyük bir açık operasyon gerekebileceğini anlatması önemlidir.

Yakın zamanlı çalışmaların büyük çoğunluğu, stabil olmayan torakolomber burst kırıklarının tedavisine perkütan tespit uygulamıştır. Bu çalışmaların büyük bölümü spinal kanalda kemik parçası retropulsiyonu ile ilişkili nörolojik semptomların olmadığı olgu serileridir. Posterior ligamentöz hasarın, bu yaklaşımın uzun dönem sonuçlarını etkileyip etkilemediği belirsizdir, ancak bazı yazarlar, geniş çaplı posterior ligamentöz hasarın posterior füzyonla daha iyi tedavi olabileceğini düşünmektedir. ${ }^{[11]}$

Çoğu instabil torakolomber burst kırığında hastanın ameliyathane masasına pron pozisyonda yatırılması sonrası travmatik deformitenin postüral olarak azalması söz konusudur. Bunu değerlendirebilmek için, hasta operasyon masasına alındıktan sonra kırık bölgesindeki sagittal dizilimin floroskopi görüntülenmesi önemlidir. Pron pozisyon sonrası düzelmeyen şiddetli angülasyon veya kifoz olgularında, uygun bir düzeltme elde etmek için anterior kolonu destekleyici girişimler veya dekompresyonun birlikte yapılabileceği şekilde açık bir yaklaşımın düşünülmesi en iyi yoldur. ${ }^{[12]}$

\section{Torakolomber Fleksiyon-Distraksiyon Tipi Kırıklar}

Literatüre bakıldığında, torakolomber burst kırıklarına göre daha az sayıda çalışma fleksiyon-distraksiyon yaralanmaları için perkütan tespite odaklanmıştır. Bu kırıkların birçoğunda kanal içi kırık parça olmamasına rağmen, posterior ligamentöz kompleks (PLC)'teki yaralanma nedenli post-travmatik kifoz deformitesi gelişme riski yüksektir ve bu hasta grubunda cerrahi stabilizasyon post-travmatik sagittal denge bozukluklarını önleme de gerekli olabilmektedir. ${ }^{[13,14]}$ PLC'nin yaralandığı bu kırıkların tüm morfolojileri TLICS (Thoraco-Lumbar Injury Classification and Severity) skorlama sistemindeki en yüksek değerleriyle yansıtılmaktadır. ${ }^{[15]}$ Burst kırılmalarından farklı olarak, cerrahideki temel hedef tipik olarak PLC hattındaki kompresyondur ve kompresyonun önemli bir kısmı hastanın ameliyat masasında pron pozisyonda konumlandırılması ile başarılır. Fleksiyon-distraksiyon tipi kırıklarda kırık yer 


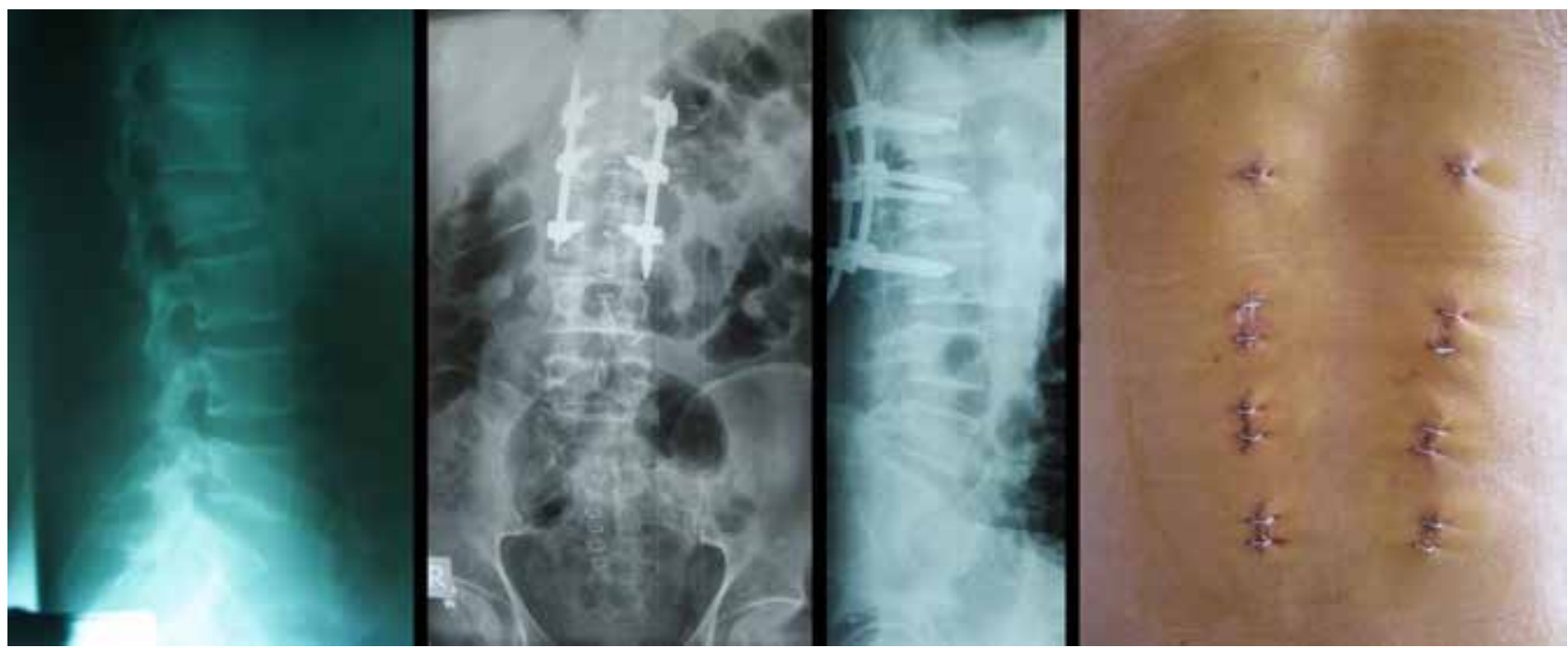

Şekil 1. Otuz sekiz yaşında erkek hastanın, araç içi trafik kazası nedeniyle oluşan L2 vertebra kırığına kapalı redüksiyon ve minimal invaziv olarak perkütan enstrümantasyon uygulandı. En sağdaki resimde hastanın ameliyat sonrası insizyonları görülmekte.

değiştirmesini ve/veya nörolojik hasarın kötüleşmesini önlemek için rod yerleştirme sırasında distraksiyon manevralarından kaçınılmalıdır.

Perkütan pedikül vidası tespiti ile başarılan internal breysleme, kırık hattındaki hareketi önleyerek iyileşme sürecini hızlandırırken, özellikle sağlıklı genç hastalarla ve kırık açık redüksiyonu gerektirmeyen hastalarda güvenli stabilizasyon sağlar. Grossbach ve ark.'nın yaptıkları çalışmada, fleksiyon-distraksiyon kırıklarında perkütan tespit uygulamasının güvenli olduğu, daha az kan kaybı, daha kısa ameliyat ve hastanede kalış süreleri gibi avantajlarının olduğu ve takipler sırasında açık yaklaşımlara göre lokalize gelişen kifoza gidişte bir fark olmadığı gösterilmiştir (Şekil 1). ${ }^{[13]}$

\section{PERKÜTAN VERTEBRAL AUGMENTASYON}

Torakolomber kırıklı bazı olgularda posterior spinal tespit yeterli olmayabilir veya ileri yaş ve/veya ciddi osteoporoz gibi nedenlerle kontrendike olabilir. 1980'li yıllardan beri, polimetilmetakrilat (PMMA) çimentosunun perkütan enjeksiyonundan oluşan vertebroplasti ve kifoplasti teknikleri kullanılmaktadır.

Vertebroplasti tekniğinin torakolomber kırıklı hastalarda kullanıldığında bazı hastalarda ağrı seviyelerini arttırabildiği, aynı zamanda vertebra korpusu dışına PMMA kaçışı ve buna bağlı olarak nörolojik defisitlere ve/veya pulmoner emboliye neden olabileceği gösterilmiştir. ${ }^{[16,17]}$ Balon kifoplastinin kırıklarda kullanımının vertebroplastiye üstün olduğunu bildiren çalışmalar mevcuttur. Perkütan transpediküler yolla vertebra gövdesi içine girilerek, çimento enjeksiyonu için bir boşluk oluşturmak üzere balonun şişirildiği kifoplasti tekniğinin teorik olarak düşük basınçlı çimento enjeksiyonuna izin vermesi dolayısıyla PMMA kaçışı ve embolizasyon gibi risklerin daha az olduğu bildirilmektedir. ${ }^{[18]}$

Kifoplasti tekniğinin avantajı olarak travma sonrası yüksekliğini kaybeden vertebral cismin genişlemesinin vertebroplastiye göre daha fazla olduğu ve sonuçta iyileşmenin daha iyi gerçekleştiği iddiaları vardır; ancak, karşılaştırmalı çalışmalardaki veriler vertebroplasti ve balon kifoplasti arasında anlamlı bir fark olmadığını göstermektedir. ${ }^{[18,19]}$

\section{Torakolomber Mini-Açık Lateral Yaklaşımlar}

Torakolomber kırıklarda kırık parça veya parçalar sıklıkla spinal kanalı daraltıcı şekilde retropulsedir. Kanal içi parça varlığında, nörolojik hasar olabilir veya hasta nörolojik olarak tamamen intakt olabilir. Posterior ve posterolateral yaklaşımlar, posterior elemanların dekompresyonuna izin vermesi, nöral elemanların net olarak görülebilmesi için geniş bir alan sağlaması, aynı zamanda pedikül vidası tespiti ve posterolateral artrodeze imkân sağlaması nedeniyle birçok cerrah için standart tedavidir. Anterior spinal yaklaşımlar ise cerrahın patolojinin olduğu bölgeyi doğrudan görmesine ve hemen hemen tüm durumlarda nöral elemanlara ventralden hakim olunarak dekompresyonun sağlanmasına izin verir. Nörolojik hasarı olan kırıklarda anterior yaklaşımların daha iyi nörolojik sonuçlarının olduğunu bildiren çalışmalar mevcuttur. ${ }^{[20,21]}$ Ayrıca, 
posterior yaklaşımlarla anterior kolona erişim sırasında gerekli olan omurilik ve sinir kök retraksiyonu ihtiyacı anterior yaklaşımlarda ortadan kalkmaktadır. ${ }^{[22]}$ Anterior kolon desteğini sağlayan implant teknolojilerin gelişmesiyle; anterior kolonun restorasyonu daha iyi sağlanabilir, biyomekanik olarak daha iyi füzyon oranları, daha düşük çökme oranları ile posttravmatik kifoz riskinin azaltılması başarılabilir.

Retropulse kemik parçalarının çıkarılmasını gerektiren nörolojik semptomları olan torakolomber kırıklı hastalarda anterolateral yaklaşımla korpektomi uygulaması ve sagittal dizilimin sağlanması amaçlı anterior kolon desteği uygulamalarının, posterior yaklaşımlara tercih edilmesi gerektiği bildirilmiştir. Özellikle uzun yaşam beklentisi olan genç hastalarda geç dönemde gözlenen sagittal dengesizlik ve spinal deformitenin hayat kalitesini olumsuz yönde etkilediği kanıtlanmıştır. ${ }^{[23]}$

Orjinal olarak dejeneratif omurga hastalıklarının tedavisi için tasarlanmış olan mini-açık lateral yaklaşımlar, anterior kolona yaklaşmayı gerektiren uygulamalarda travma dahil olmak üzere enfeksiyöz ve neoplastik lezyonlarda da benimsenmiştir.

Mini-açık lateral yaklaşımlar, geleneksel transtorasik ve retroperitoneal yaklaşımlarla karşılaştırıldığında, floroskopik kılavuz altında patolojiye direkt erişim sağlamak için retraktörleri kullanır. Bu yaklaşımların ortaya çıkmasındaki en önemli neden, açık anterior yaklaşımların ağrı ve kan kaybına bağlı olan morbiditesinin azaltılmasıdır. Ayrıca, mini-açık lateral girişimlerde torakal omurlara retroplevral olarak yaklaşıldığından, açık transtorasik torakotomilerde gerekli olan plevral boşluğun açılması engellenmiş olur ve standart çift lümenli ventilasyona izin verilir. Aynı zamanda dura yaralanmaları sonucu gelişen duroplevral beyin-omurilik sıvısı fistülü gelişme olasılığı da azaltılmış olur. ${ }^{[22]}$

Özgür ve ark. tarafindan lomber omurga dejeneratif hastalıkları için tanımlanmış mini-açık lateral yaklaşım tekniği (Extreme Lateral Interbody Fusion -XLIF) lomber travmada da aynen kullanılabilir. ${ }^{[24]}$ Torakolomber bileşke ve torakal omurga travmaları için, retroplevral olarak erişimin mümkün olduğu minimal invaziv retroplevral torakolomber yaklaşım tanımlanmıştır. ${ }^{[25]}$

Smith ve ark.'nın ${ }^{[26]}$ T7 ve L4 omurları arasında tek seviyeli korpektomiler ile tedavi edilen 52 hastalık travma serisinde, anterior destek ve füzyon için titanyum kafesler ve lateral plak tespiti uygulanmış ve birkaç olgu ek pedikül vidası tespiti ile posteriordan desteklenmiştir. Genel komplikasyon oranları \%15 olarak bildirilmiştir ve tüm hastalar nörolojik olarak stabil kalmışlardır. Yine aynı çalışmada yazarlar, kullanılan silindirik yapıdaki titanyum kafeslerde bir miktar çökmenin olmasına rağmen dikdörtgen şekilli kafeslerde herhangi bir çökme gözlenmediğini bildirmişlerdir.

Baaj ve ark.'nın ${ }^{[27]}$ travma, enfeksiyon ve tümörler için minimal invaziv yöntemlerle korpektomi geçiren 80 hastadan oluşan serilerinde ise toplam komplikasyon oranı \%12,5 olarak verilirken bu komplikasyonların dura hasarları, interkostal nevralji, derin ven trombozu, plevral effüzyon, hemotoraks, yara enfeksiyonu ve implant yetmezliği olduğu bildirilmiştir.

İnstabil 12 lomber burst kırığında minimal invaziv korpektomilere odaklanan bir başka çalışma, bu yöntemin kısa segment posterior tespit ile desteklendiğinde lokal lordozun daha iyi sağlandığını, iyi hasta memnuniyeti, minimal ağrı ve azalmış morbidite ile iyi tolere edildiğini göstermiştir. ${ }^{[28]}$

Mini-açık lateral yaklaşımların kısıtlılıklarından en önemlisi posterior elemanlara ulaşmanın mümkün olmamasıdır. Korpus kırığına eşlik eden posterior ark yaralanmalarında ve/veya buna bağlı kök basısı gibi durumlarda açık posterior yaklaşım tercih edilir. Ayrıca, en uygun erişim bölgesi T6-L4 arasıdır, T6 kraniyalinde skapula ve L4 kaudalinde iliak kanat bulunduğu için sınırlı erişim sağlanır. Lomber seviyelerde psoas kasının manipülasyonu sırasında lumbosakral pleksusun risk altında olması bir diğer dezavantaj olarak sayılabilir. Obez hastalarda, hem cerrahi alana ulaşmanın zorluğu hem de ameliyat sırasında görüntüleme kalitesinin düşmesi nedeniyle tercih edilmez. Yine cerrahi yaklaşımın kendisi ile ilgili olarak, minimal invaziv tekniklerin floroskopik görüntülemeye bağımlı olması, retroperitoneal/retroplevral retraktör yerleştirmenin zorluğu ve derin, dar bir alanda çalışmak zorunda kalınması gibi zorluklardan dolayı, uzun bir öğrenme eğrisinin olduğu söylenebilir. Bu prosedürün geleneksel açık korpektomi teknikleri hakkında tecrübe sahibi omurga cerrahları tarafından yapılması komplikasyon oranlarını azaltacaktır.

\section{SONUÇ}

Minimal invaziv omurga tekniklerinin uygun stabilizasyon sağladığı yönünde fikir birliği olmasına rağmen, artrodez olmaksızın bu stabilizasyonun devam edip edemeyeceği en çok tartışılan konuların başında gelmektedir. Kesin veriler hala posterolateral artrodez olmaksızın uzun süreli tespiti desteklemiyor olsa da, çoğu klinik durumda implantlar çıkarıldıktan sonra bile uzun dönemde kifoz riskinde artış olmadığını bildiren çalışmalar ortaya çıkmaktadır. Perkütan pedikül vida yardımlı posterior tespitin, paravertebral kasların ve innervasyonun korunması, kan akımının bozulmaması gibi avantajlarla iyileşmeyi hızlandıırken uygun stabilizasyonu sağladığı 
yönündeki teorilerin doğruluğu olasıdır. Nöral bası ve buna bağlı semptomatik bulguları olan kırıklarda mini-açık lateral yaklaşımlar, hem ventraldeki retropulse parçaların güvenli bir şekilde çıkarılmasına, hem de ön kolonun uygun implantlarla desteklenmesine olanak sağlarken, geleneksel anterior yaklaşımlara kıyasla ağrı, kan kaybı ve morbiditeyi en aza indirir.

\section{KAYNAKLAR}

1. Vanek P, Bradac O, Konopkova R, de Lacy P, Lacman J, Benes $V$. Treatment of thoracolumbar trauma by shortsegment percutaneous transpedicular screw instrumentation: prospective comparative study with a minimum 2- year follow-up. J Neurosurg Spine 2014;20(2):150-6. Crossref

2. Wild $M H$, Glees $M$, Plieschnegger $C$, Wenda K. Five-year follow-up examination after purely minimally invasive posterior stabilization of thoracolumbar fractures: a comparison of minimally invasive percutaneously and conventionally open treated patients. Arch Orthop Trauma Surg 2007;127(5):335-43. Crossref

3. Walker CT, Xu DS, Godzik J, Turner JD, Uribe JS, Smith WD. Minimally invasive surgery for thoracolumbar spinal trauma. Ann Transl Med 2018;6(6):102. Crossref

4. Court C, Vincent C. Percutaneous fixation of thoracolomber fractures: current concepts. Orthop Traumatol Surg Res 2012;98(8):900-9. Crossref

5. Wang ST, Ma HL, Liu CL, Yu WK, Chang MC, Chen TH. Is fusion necessary for surgically treated burst fractures of the thoracolumbar and lumbar spine?: a prospective, randomized study. Spine (Phila Pa 1976) 2006;31(23):2646-52. Crossref

6. Tezeren $G$, Bulut $O$, Tükenmez M, Öztürk H, Oztemur Z, Ozturk A. Long segment instrumentation of thoracolumbar burst fracture: fusion versus nonfusion. J Back Musculoskelet Rehabil 2009;22(2):107-12. Crossref

7. Palmisani M, Gasbarrini A, Brodano GB, De lure F, Cappuccio $\mathrm{M}$, Boriani L, Amendola L, Boriani S. Minimally invasive percutaneous fixationin the treatment of thoracic and lumbar spine fractures. Eur Spine J 2009;18 Suppl 1:71-4. Crossref

8. Yang H, Shi JH, Ebraheim M, Liu X, Konrad J, Husain I, Tang TS, Liu J. Outcome of thoracolumbar burst fractures treated with indirect reduction and fixation without fusion. Eur Spine J 2011;20(3):380-6. Crossref

9. Van der Roer N, de Lange ES, Bakker FC, de Vet HC, van Tulder MW. Management of traumatic thoracolumbar fractures: a systematic review of the literature. Eur Spine J 2005;14(6):527-34. Crossref

10. Phan K, Rao PJ, Mobbs RJ. Percutaneous versus open pedicle screw fixation for treatment of thoracolumbar fractures: Systematic review and meta-analysis of comparative studies. Clin Neurol Neurosurg 2015;135:85-92. Crossref

11. Koreckij T, Park DK, Fischgrund J. Minimally invasive spine surgery in the treatment of thoracolumbar and lumbar spine trauma. Neurosurg Focus 2014;37(1):E11. Crossref

12. Jiang XZ, Tian W, Liu B, Li Q, Zhang GL, Hu L, Li Z, He D. Comparison of a paraspinal approach with a percutaneous approach in the treatment of thoracolumbar burst fractures with posterior ligamentous complex injury: a prospective randomized controlled trial. J Int Med Res 2012;40(4):1343-56. Crossref

13. Grossbach AJ, Dahdaleh NS, Abel TJ, Woods GD, Dlouhy BJ, Hitchon PW. Flexion-distraction injuries of the thoracolumbar spine: open fusion versus percutaneous pedicle screw fixation. Neurosurg Focus 2013;35(2):E2. Crossref
14. Schizas C, Kosmopoulos V. Percutaneous surgical treatment of chance fractures using cannulated pedicle screws. Report of two cases. J Neurosurg Spine 2017;7(1):71-4. Crossref

15. Vaccaro AR, Lehman RA Jr, Hurlbert RJ, Anderson PA, Harris M, Hedlund R, Harrop J, Dvorak M, Wood K, Fehlings MG, Fisher C, Zeiller SC, Anderson DG, Bono CM, Stock GH, Brown AK, Kuklo T, Öner FC. A new classification of thoracolumbar injuries: the importance of injury morphology, the integrity of the posterior ligamentous complex, and neurologic status. Spine (Phila Pa 1976) 2005;30(20):2325-33. Crossref

16. Heini PF, Walchli B, Berlemann U. Percutaneous transpedicular vertebroplasty with PMMA. operative technique and early results. A prospective study for the treatment of osteoporotic compression fractures. Eur Spine J 2000;9(5):445-50. Crossref

17. Hu KZ, Chen SC, Xu L. Comparison of percutaneous balloon dilation kyphoplasty and percutaneous vertebroplasty in treatment for thoracolumbar vertebral compression fractures. Eur Rev Med Pharmacol Sci 2018;22(1 Suppl):96-102. Crossref

18. Burton AW, Rhines LD, Mendel E. Vertebroplasty and kyphoplasty: a comprehensive review. Neurosurg Focus 2005;18(3):e1. Crossref

19. Liu JT, Li CS, Chang CS, Liao WJ. Long-term follow-up study of osteoporotic vertebral compression fracture treated using balloon kyphoplasty and vertebroplasty. J Neurosurg Spine 2015;23(1):94-8. Crossref

20. Kaneda K, Taneichi H, Abumi K, Hashimoto T, Satoh S, Fujiya M. Anterior decompression and stabilization with the Kaneda device for thoracolumbar burst fractures associated with neurological deficits. J Bone Joint Surg Am 1997;79(1):6983. Crossref

21. Zhu Q, Shi F, Cai W, Bai J, Fan J, Yang H. Comparison of Anterior Versus Posterior Approach in the Treatment of Thoracolumbar Fractures: A Systematic Review. Int Surg 2015;100(6):1124-33. Crossref

22. McCormick PC. Retropleural approach to the thoracic and thoracolumbar spine. Neurosurgery 1995;37(5):908-14. Crossref

23. Vaccaro AR, Silber JS. Post-traumatic spinal deformity. Spine (Phila Pa 1976) 2001;26(Suppl):S111-8. Crossref

24. Ozgur BM, Aryan HE, Pimenta L, Taylor WR. Extreme Lateral Interbody Fusion (XLIF): a novel surgical technique for anterior lumbar interbody fusion. Spine J 2006;6(4):435-43. Crossref

25. Uribe JS, Dakwar E, Cardona RF, Vale FL. Minimally invasive lateral retropleural thoracolumbar approach: cadaveric feasibility study and report of 4 clinical cases. Neurosurgery 2011;68(Suppl 1):ons32-9. Crossref

26. Smith WD, Dakwar E, Le TV, Christian G, Serrano S, Uribe JS. Minimally invasive surgery for traumatic spinal pathologies: a mini-open, lateral approach in the thoracic and lumbar spine. Spine (Phila Pa 1976) 2010;35(26S):S338-46. Crossref

27. Baaj AA, Dakwar E, Le TV, Smith DA, Ramos E, Smith WD, Uribe JS. Complications of the mini-open anterolateral approach to the thoracolumbar spine. J Clin Neurosci 2012;19(9):1265-7. Crossref

28. Theologis AA, Tabaraee E, Toogood P, Kennedy A, Birk H, McClellan RT, Pekmezci M. Anterior corpectomy via the miniopen, extreme lateral, transpsoas approach combined with short-segment posterior fixation for single-level traumatic lumbar burst fractures:analysis of health-related quality of life outcomes and patient satisfaction. J Neurosurg Spine 2016;24(1):60-8. Crossref 